\title{
DEBATES NECESSÁRIOS: AMBIENTE, EDUCAÇÃO E DIVERSIDADES
}

\section{ESSENTIAL DEBATES: ENVIRONMENT, EDUCATION AND DIVERSITIES}

Roberta Ferreira Coelho de Andrade ${ }^{1}$, Aldair Oliveira de Andrade ${ }^{2}$, Antonio Marcos de Oliveira Siqueira ${ }^{3}$, Wagner dos Reis Marques Araújo ${ }^{4}$

1 Departamento de Serviço Social, Universidade Federal do Amazonas, Manaus/AM, Brasil, roberta ufam@yahoo.com.br

2 Programa de Pós-Graduação em Ciências e Humanidades (PPGCH), Universidade Federal do Amazonas, Humaitá/AM, Brasil, aldairandrade@yahoo.com.br

${ }_{3}^{3}$ Universidade Federal de Viçosa, Viçosa/MG, Brasil, antonio.siqueira@ufv.br

${ }^{4}$ Universidade do Estado de Minas Gerais, UEMG-Abaeté/MG, Brasil, marquesreis@hotmail.com

\section{A R T I C LE IN F O}

Article history:

Received 2020-02-10

Accepted 2020-02-20

Available online 2020-02-20
Palavras-chave: Ambiente. Educação. Gênero. Discurso Midiático. História.

Keywords: Environment. Education. Genre. Media Discourse. History.

Num contexto em que o mundo é assombrado por uma pandemia, mais do que nunca precisamos defender os pesquisadores e as instituições que se ocupam em fazer ciência, pois, graças ao conhecimento científico, ao longo da história, tem sido possível responder a demandas sociais, explicar e interpretar a realidade e indicar caminhos e respostas para o enfrentamento dos grandes problemas que assolam a humanidade.

A Revista Relações Sociais acredita que a socialização do conhecimento é um meio relevante e necessário para superação das visões estreitas e enviesadas da realidade, para a não resignação ante à lógica dominante, pois, nessa perspectiva, a troca, a reflexão, o questionamento e a construção de novas proposições favorecem a caminhada rumo a uma educação emancipatória, que tem em seu horizonte a superação das estruturas sociais desiguais, a construção de uma sociedade que vá além do capital, como propõe Mészaros (2008).

Neste primeiro número do terceiro volume temos a oportunidade de refletir sobre uma diversidade de temáticas: ambiente, educação, gênero, discurso midiático e história. Tais temáticas nos evidenciam a necessidade de superação dos estereótipos, dos preconceitos (de classe, raça/etnia, de orientação sexual etc.), da lógica destrutiva do ambiente, o que 
implica caminhar em direção à construção de uma sociedade mais justa, menos desigual, em suma, rumo à emancipação humana do jugo do capital que escraviza e coisifica a existência.

Neste cenário, mais do que nunca, somos convidados à reflexão sobre os pressupostos da modernidade (NIETZSCHE, 2003), marcada por uma fluidez (BAUMAN, 2001), por relações cada vez mais líquidas, efêmeras. Por isso, precisamos nos descoisificar, nos construir como sujeitos esclarecidos (ADORNO e HORKHEIMER, 1985), que pensam, questionam, produzem conhecimento, fazem uso da racionalidade ambiental, como propõem Leff (2001) e Morin (2000) e, assim, reconhecem que homem e natureza estão entrelaçados.

No artigo "Análise comparativa dos relatórios socioambientais de 2013 e 2016 de empresas participantes do Programa 'Em boa companhia”, Deisy Cristina Corrêa Igarashi, Adriel da Costa Benati, Flávia Mayara Segate, Bárbara Johann Borges e Wagner Igarashi trazem a discussão sobre a atuação das empresas analisadas. Quanto aos eixos em estudo, verificou-se que todas as empresas apresentaram atuação nos eixos Planeta e Prosperidade, nos de 2013 e 2016, respectivamente. No eixo Pessoas, a Empresa Duratex apresenta atuação em 2013 e 2016, sendo que, Suzano e Klabin somente em atuação em 2016. No eixo Parceria, identificou-se atuação de todas as empresas em algum dos anos, sendo Duratex a única a atuar em 2013 e 2016, enquanto Suzano apresentou atuação em 2013 e Kablin em 2016.

Em "Trajetórias e experiências escolares de estudantes cotistas negros/as da UNILAB: identidades, currículo e práticas pedagógicas", Francisco Érick de Oliveira põe em voga o tema do sucesso escolar de estudantes negros/as, cotistas, das camadas populares e de cursos de graduação através de uma metodologia disposicionalista. Por meio de trajetórias e narrativas (auto)biográficas, o autor procurou reconstruir cenários de socialização de disposições de longevidade escolar, a fim de compreender como se constituíram possibilidades de acesso ao ensino superior em condições socioeconômicas e culturais sociologicamente desfavoráveis. O autor encontrou configurações familiares em que a vida está articulada ao campo escolar, com atividades extraescolares que intensificaram a formação de habitus que interliga vida e educação, por meio do envolvimento em programas, projetos e políticas públicas.

Suélem do Sacramento Costa de Moraes e Bárbara Hees Garré, em "Discussões acerca do discurso midiático contemporâneo: a fabricação do corpo magro na Revista Anamaria", problematizam as discursividades em disputa no mundo da moda e da estética. Ao analisarem os discursos presentes numa das seções da revista dedicada a dietas, 
identificam a cooperação para a construção de um modelo impositivo de beleza, inexoravelmente magro.

"Coligay e as memórias dos torcedores do Grêmio", de Gustavo Andrada Bandeira e Fernando Seffner, é um convite à compreensão das manifestações associadas ao futebol e às representações de gênero. Segundo os autores, as manifestações verbais no Brasil passaram a ser colocadas em questão, sendo impostas em 2016 sanções pela FIFA. Os autores vislumbram em certa medida uma ressurreição da torcida homossexual do Clube Grêmio, com a produção de um livro e um curta metragem sobre a torcida organizada entre o final da década de 1970 e início de 1980. Para os autores, os embates do presente produzem ressignificações acerca do passado das torcidas e da história dos clubes, em particular acionando os marcadores gênero e sexualidade.

O debate proposto em "Gênero e diagnóstico em saúde mental: que relação é essa?", de Muriel Closs Boeff e Tatiana Camargo de Souza, remete à abordagem das questões de gênero no momento da realização de um diagnóstico. $O$ estudo de caso delineou-se pela adoção de entrevistas, observação e diário de campo, com moradores de uma cidade do Rio Grande do Sul. Para os autores, é necessário demonstrar que antes de oferecer espaços de voz, é necessário repensar as relações de poder e dominação exercidas pelos profissionais que diagnosticam, questionando se o processo não seria reflexo de uma medicalização do sofrimento feminino. Em justa medida, é fundamental um olhar atento ao processo diagnóstico, muitas vezes realizado sem qualquer questionamento às inúmeras situações de violência e opressão de gênero.

"Sobre aquilo que (não) se fala: 'eu não sou esse... gay que levanta a bandeira pelo próprio corpo"', de Paula Hosana Silveira Biazus e Vantoir Roberto Brancher, debate as significações imaginárias da docência e os trajetos formativos de docentes LGBT. Os autores problematizaram e direcionam a atenção à relação que o docente realiza com sua noção de corpo, as transformações do termo homossexualidade e seus impactos no contexto escolar. Para os autores, repensar os limites impostos aos corpos, a partir de suas falas, tem potencial de conduzir à desmistificação do binarismo e das associações naturalizadas entre sexo e gênero. Assim, as reflexões dos professores LGBT já compõem brechas às imagens de sujeitos que há muito são associados apenas à arte, à estética, à prostituição.

Marcos Cieslak, Rosiane Mikuska, Alisson Sidney Dal Santos e Carlos Alberto Marçal Gonzaga, em "Os desafios das ações sustentáveis na indústria madeireira: o caso da SPS Tecnologia Ambiental Ltda", discutem, com base em um estudo de caso por meio de entrevistas, o desenvolvimento sustentável, buscando comprovar a prática de boas intenções relacionadas com a sustentabilidade do setor madeireiro, aliando experiência, demanda local e conhecimento técnico para desenvolver novos produtos a partir da reutilização de resíduos industriais reativados, buscando resultados satisfatórios nos aspectos ambiental e econômico. 
Os autores apontam que o pré-conceito, o imediatismo e as falhas nas políticas ambientais são os principais desafios enfrentados por uma organização, ao criar novas linhas de produtos com a atual estrutura.

O artigo "A militarização como política de educação pública: um outro olhar", de Hércules Guimarães Honorato, traz a reflexão, um estudo de caso, por meio de entrevistas com gestores de colégios públicos militares do ensino médio. Os autores buscam apresentar um outro olhar sobre a militarização dos colégios públicos de ensino médio. Para os autores, alguns estereótipos sobre os estudantes e docentes militares precisam ser superados. $O$ estudo conclui que os colégios militarizados contribuem para a formação do cidadão brasileiro.

"Educação sexual para alunos/as com deficiência em Portugal: indícios de uma formação docente precária", de Ana Cláudia Bortolozzi Maia, Leilane Raquel Spadotto de Carvalho e Teresa Vilaça, revela as opiniões, sentimentos e ações sobre a Educação Sexual para alunos(as) com deficiência. Para os autores, os docentes não compreendem a educação em sala de aula como um trabalho pedagógico, temem os familiares, desconhecem as condições e recursos necessários às especificidades dos discentes. Por isso, reivindicam a necessidade de cursos de formação inicial e continuada sobre sexualidade e sobre educação para os discentes especiais. Sem isso, não é possível garantir a eficácia e o cumprimento da legislação de Educação Sexual.

Leandra de Oliveira Ferreira, Wesley Henrique Gonçalves e Wagner dos Reis Marques Araújo, em "Análise do cultivo de café em Espera Feliz (MG) em meados do século XX", incitam o debate acerca da identificação das características agrícolas e características de produtos de região agrícola de Minas Gerais. A pesquisa, uma análise estatística da produção agrícola, concluiu que a economia de Espera Feliz partiu do cultivo do café como produto de exportação, influenciando o crescimento socioeconômico local, projetando o município como uma rica região produtora de cafés especiais.

\section{REFERÊNCIAS}

ADORNO, Theordor, HORKHEIMER, Max. Dialética do Esclarecimento 1985.

BAUMAN, Zygmunt. Modernidade líquida Rio de Janeiro: Jorge Zahar Ed. 2001.

LEFF, Henrique. Epistemologia ambiental. São Paulo, Cortez Editora, 2001.

MÉSZÁROS, István. A Educação para além do capital. 2. ed. São Paulo: Boitempo, 2008.

MORIN, Edgar. Os sete saberes necessários à educação do futuro. Tradução de Catarina

Eleonora F. da Silva e Jeanne Sawaya. 2. ed. - São Paulo: Cortez, 2000.

NIETZCHE, Friedrich. Escritos sobre Educação. Tradução, apresentação e notas; Noéli Correia de Melo Sobrinho. São Paulo: Edições Loyola, 2003. 